\title{
Dexmedetomidine as a promising prevention strategy for cardiac surgery-associated acute kidney injury: a meta-analysis
}

\author{
Rui Shi ${ }^{1}$ and Hong-Tao Tie ${ }^{2^{*}}$
}

Keywords: Cardiac surgery, Acute kidney injury, Dexmedetomidine, Meta-analysis

Dexmedetomidine has a possible protective effect on cardiac surgery-associated acute kidney injury (CSA-AKI); however, current evidence is limited and controversial. We therefore conducted a meta-analysis regarding dexmedetomidine for CSA-AKI.

PubMed and EMbase were searched. A random-effects model in RevMan 5.3 software was used, and $P<0.05$ indicates statistical significance. Three randomized controlled trials (RCTs) with 338 patients and four cohort studies involving 19,266 participants were included. The main characteristics are shown in Table 1 . Overall results show that dexmedetomidine was associated with a significantly reduced incidence of CSA-AKI in both the RCTs (relative risk [RR] 0.44, 95\% confidence interval [CI] 0.26-0.76, $p=0.003$ ) and cohort studies (RR 0.74, 95\% CI 0.63-0.86, $p=0.0001$ ) (Fig. 1) without significant heterogeneity (RCT $I^{2}=0 \%$; cohort $I^{2}=0 \%$ ). For secondary outcomes, dexmedetomidine failed to decrease postoperative mortality (RCT RR 0.20 , 95\% CI 0.02-1.68; cohort RR 0.56, 95\% CI 0.28-1.15), duration of mechanical ventilator (RCT standard mean differences [SMD] -0.18, 95\% CI -2.08-1.71; cohort SMD -0.12, 95\% CI -0.25-0.01), intensive care unit stay (RCT SMD $-0.21,95 \%$ CI $-0.53-0.11$; cohort SMD -0.52 , 95\% CI -1.06-0.02), and hospital length of stay (SMD -0.34 , 95\% CI -1.21-0.54). However, decreased trends were observed for all secondary outcomes.

\footnotetext{
* Correspondence: hongtaotie@163.com

2Department of Cardiothoracic Surgery, The First Affiliated Hospital of

Chongqing Medical University, Chongqing 400016, China

Full list of author information is available at the end of the article
}

A retrospective cohort study [1] and an RCT [2] were not consistent with the other included studies in our meta-analysis. This inconsistency could be explained by limitations of retrospective studies, different CSA-AKI criteria, different doses and duration of dexmedetomidine for the cohort, and CSA-AKI criteria for the RCT because the preventive effect was found when defined by NGAL concentration but not RIFLE classification.

The underlying mechanism is multifactorial, and current evidence demonstrates that, as a selective $\alpha 2$ adrenoreceptor agonist, the renoprotective function of dexmedetomidine could be achieved by promoting renal blood flow via inhibiting vasoconstriction and promoting a diuresis effect via decreasing renin and arginine vasopressin and increasing glomerular filtration [3]. Additionally, protection from kidney ischemia/reperfusion injury by reducing reactive oxygen species, decreased systemic inflammatory response, and reduced renal cell death in cardiac surgery were also involved [4].

Hypotension and bradycardia caused by dexmedetomidine are often of concern, mainly with loading and maintenance doses $>0.7 \mu \mathrm{g} / \mathrm{kg} / \mathrm{h}$ [5]. All reported dexmedetomidine doses were lower than $0.7 \mu \mathrm{g} / \mathrm{kg} / \mathrm{h}$ in our meta-analysis except for two unknown cohorts. Additionally, dexmedetomidine's safety and efficacy have been confirmed in cardiac surgery [1].

In summary, dexmedetomidine might be a promising prevention strategy for CSA-AKI. More high-quality RCTs are encouraged to verify the beneficial effect of dexmedetomidine before its clinical application. 


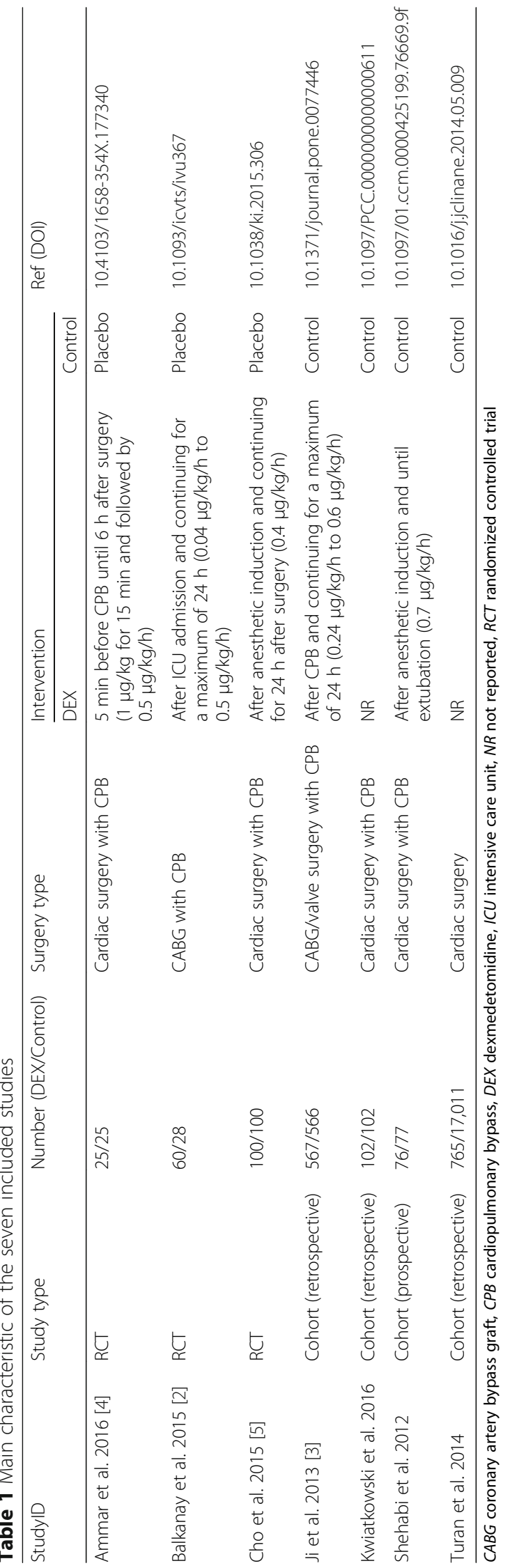




\begin{tabular}{|c|c|c|c|c|c|c|c|c|c|c|}
\hline Study or Subgroup & $\begin{array}{c}\text { DEX } \\
\text { Events }\end{array}$ & Total & $\begin{array}{c}\text { Con } \\
\text { Events }\end{array}$ & ${ }^{n}$ Total & Weight & $\begin{array}{c}\text { Risk Ratio } \\
\text { M-H, Random, } 95 \% \mathrm{Cl}\end{array}$ & & $\begin{array}{r}\quad \text { Risk } \\
M-H, \text { Rand }\end{array}$ & $\begin{array}{l}\text { Ratio } \\
\text { dom. } 95 \% \mathrm{Cl}\end{array}$ & \\
\hline \multicolumn{11}{|l|}{ Cohort studies } \\
\hline David 2016 & 24 & 102 & 36 & 102 & $12.5 \%$ & $0.67[0.43,1.03]$ & & & & \\
\hline Ji 2014 & 148 & 567 & 191 & 566 & $73.7 \%$ & $0.77[0.65,0.93]$ & & & & \\
\hline Shehabi 2012 & 10 & 76 & 21 & 77 & $5.1 \%$ & $0.48[0.24,0.96]$ & & & & \\
\hline Turan 2014 & 14 & 765 & 425 & 17011 & $8.6 \%$ & $0.73[0.43,1.24]$ & & $\rightarrow$ & & \\
\hline Total $(95 \% \mathrm{Cl})$ & & 1510 & & 17756 & $100.0 \%$ & $0.74[0.63,0.86]$ & & $\checkmark$ & & \\
\hline $\begin{array}{l}\text { Total events } \\
\text { Heterogeneity: } \text { Tau }^{2}= \\
\text { Test for overall effect }\end{array}$ & $\begin{array}{c}196 \\
0.00 ; \mathrm{Chi}^{2} \\
Z=3.85(P\end{array}$ & $\begin{array}{l}=1.96 \\
P=0.06\end{array}$ & $\begin{array}{l}\quad 673 \\
d f=3(P \\
001)\end{array}$ & $=0.58)$ & $; 1^{2}=0 \%$ & & & . & . & \\
\hline \multicolumn{11}{|c|}{ Randomized Control Trials } \\
\hline Ammar 2016 & 0 & 25 & 0 & 25 & & Not estimable & & & & \\
\hline Balkanay 2015 & 2 & 60 & 1 & 28 & $5.3 \%$ & $0.93[0.09,9.87]$ & & & & \\
\hline Cho 2016 & 14 & 100 & 33 & 100 & $94.7 \%$ & $0.42[0.24,0.74]$ & & & & \\
\hline Total $(95 \% \mathrm{CI})$ & & 185 & & 153 & $100.0 \%$ & $0.44[0.26,0.76]$ & & & & \\
\hline Total events & 16 & & 34 & & & & & & & \\
\hline \multicolumn{7}{|c|}{$\begin{array}{l}\text { Heterogeneity: } \mathrm{Tau}^{2}=0.00 ; \mathrm{Chi}^{2}=0.41, \mathrm{df}=1(\mathrm{P}=0.52) ; \mathrm{I}^{2}=0 \% \\
\text { Test for overall effect: } Z=2.93(\mathrm{P}=0.003)\end{array}$} & 0.01 & $\begin{array}{l}0.1 \\
\text { Favours DEX }\end{array}$ & 1 Favours Con & 100 \\
\hline
\end{tabular}

\section{Abbreviations}

Cl: Confidence interval; CSA-AKI: Cardiac surgery-associated acute kidney injury; ICU: Intensive care unit; RCT: Randomized controlled trial; RR: Relative risk; SMD: Standard mean difference

\section{Acknowledgments}

None.

\section{Funding}

Cultivation Fund of The First Affiliated Hospital of Chongqing Medical University (PYJJ2017-12).

\section{Availability of supporting data}

The datasets used and analyzed during the current study are available from the corresponding author on reasonable request.

\section{Authors' contributions}

RS and HTT conceived the study, participated in the design, and collected the data. HTT performed statistical analyses. RS drafted the manuscript. HTT revised the manuscript critically for important intellectual content. Both authors read and approved the final manuscript.

\section{Authors' information}

$\mathrm{HTT}$ is now working as a cardiothoracic surgeon in the Department of Cardiothoracic Surgery, The First Affiliated Hospital of Chongqing Medical University. HTT is also the young editor of the Chinese Journal of Clinical Thoracic and Cardiovascular Surgery and section editor of the Journal of Emergency and Critical Care Medicine. His major research interests include evidence-based medicine, critical care medicine, ischemia-reperfusion injury, and perioperative organ protection.

\section{Ethics approval and consent to participate}

Not applicable.

\section{Consent for publication}

Not applicable.

\section{Competing interests}

The authors declare that they have no competing interests.

\section{Author details}

${ }^{1}$ Department of Cardiology, The First Affiliated Hospital of Chongqing Medical University, Chongqing 400016, China. ${ }^{2}$ Department of Cardiothoracic Surgery, The First Affiliated Hospital of Chongqing Medical University, Chongqing 400016, China.

Published online: 03 August 2017

\section{References}

1. Turan A, Bashour CA, You J, Kirkova Y, Kurz A, Sessler DI, et al. Dexmedetomidine sedation after cardiac surgery decreases atrial arrhythmias. J Clin Anesth. 2014;26(8):634-42.

2. Balkanay OO, Goksedef D, Omeroglu SN, Ipek G. The dose-related effects of dexmedetomidine on renal functions and serum neutrophil gelatinaseassociated lipocalin values after coronary artery bypass grafting: a randomized, triple-blind, placebo-controlled study. Interact Cardiovasc Thorac Surg. 2015;20(2):209-14.

3. Ji F, Li Z, Young JN, Yeranossian A, Liu H. Post-bypass dexmedetomidine use and postoperative acute kidney injury in patients undergoing cardiac surgery with cardiopulmonary bypass. PLoS One. 2013:8(10):e77446.

4. Ammar AS, Mahmoud KM, Kasemy ZA, Helwa MA. Cardiac and renal protective effects of dexmedetomidine in cardiac surgeries: a randomized controlled trial. Saudi J Anaesth. 2016;10(4):395-401.

5. Cho JS, Shim JK, Soh S, Kim MK, Kwak YL. Perioperative dexmedetomidine reduces the incidence and severity of acute kidney injury following valvular heart surgery. Kidney Int. 2016;89:693-700

\section{Publisher's Note}

Springer Nature remains neutral with regard to jurisdictional claims in published maps and institutional affiliations. 